\title{
Dos Subúrbios Citadinos aos Subúrbios Metropolitanos Estrutura de povoamento e morfogénese da metrópole de Lisboa (1950-2001)
}

\section{João Pedro Silva Nunes*}

Resumo: Em cinquenta anos, os arredores de Lisboa urbanizaram-se. Pequenos núcleos suburbanos, associados à indústria, à residência e à vilegiatura deram lugar a vastos corredores de expansão e consolidação metropolitana onde uma pluralidade de formas de ocupação, de circulação e de uso hoje se observa. Através da análise à transformação dos padrões de concentração populacional na aglomeração de Lisboa, este artigo dá conta de como na segunda metade do século Xx emergiu e se consolidou uma estrutura de povoamento que em muito contribuiu para a morfogénese da metrópole de Lisboa.

Palavras-chave: Lisboa; Metrópole; Subúrbio; Estrutura de Povoamento.

\section{Introdução}

É bem conhecido o processo de urbanização de Lisboa. Por um lado, os modos e caminhos da urbanização da capital foram bem detalhados e interpretados por Vítor Matias Ferreira (1987). Através daquelas duas vias, o autor deu conta das origens e dos efeitos da transformação da cidade que durante um ciclo de urbanização moldaram o destino de Lisboa: de cidade Oitocentista a "do Império" e, mais tarde, a "da Metrópole". Por outro lado, um particular e elucidativo processo de "invenção da cidade" Lisboa foi analisado por Luís Baptista (1997 e 1999). A habitação económica, elaborada material e ideologicamente pelo Estado Novo, definiu espaços urbanos e residenciais, elegeu populações e compôs e recompôs partes da capital e dos seus arredores, participando assim sobretudo, ao longo da segunda metade do século passado - na constituição de Lisboa "contexto metropolitano" (Baptista, 1994). Do trabalho destes dois autores sobressai a rapidez do crescimento urbano registado em Lisboa e em seu redor, a pluralidade das suas formas e destinações sociais e o grau de concentração populacional atingido ao longo de mais de um século.

É menos conhecido o processo de suburbanização de Lisboa. Ainda assim, a intensidade e os contornos desta importante transformação urbana encontram-se, por exemplo, bem patentes nos contributos pioneiros de Maria Alfreda Cruz (1973) sobre a urbanização das povoações da margem sul do estuário do Tejo ou de Álvaro Corte-Real (1973) sobre Fetais, Pontinha e Santo António dos Cavaleiros. A transformação radical dos arredores de Lisboa constituiu o pano de fundo de uma avaliação sistemática que Margarida Sousa Lobo e Nuno Portas (1970) empreenderam sobre os níveis de qualidade urbanística no "subúrbio de Lisboa-cidade" na década de 1960. Lugares como a Amadora e Queluz, como a Cova da Piedade e o Laranjeiro, ou como Rio de Mouro, o Cacém e Odivelas evidenciavam aos olhos dos analistas da época e dos residentes na grande cidade e nos seus arredores um forte crescimento que recortava uma significativa "assimetria" de "meios de vida" urbana (Portas e Lobo, 1970). Nas décadas seguintes, estes e outros lugares, associados a um forte crescimento urbano, multiplicaram-se e concentraram contingentes populacionais que foram atingindo, década após década, ordens de grandeza superior. Trata-se, para Luís Baptista (2009), da “densificação das áreas que antes eram o limiar da vida urbana, enquanto zonas de passagem para o interior da urbe, zonas de recreio para os citadinos, zonas de apoio à manutenção alimentar e serviçal da vida intramuros" que se urbanizam e assim que se "autonomiza $(m)$ na forma e nos modos de vida, suburbanos" (2009: 35). 
Perspectivada a partir do processo de urbanização, esta mudança corresponde ao crescimento demográfico no território da aglomeração de Lisboa e à multiplicação dos lugares onde o povoamento se concentra, ao longo do tempo, nos arredores da cidade. Perspectivada a partir do processo de suburbanização, esta mudança surge associada aos volumes populacionais e aos intensos ritmos de crescimento que alteraram a condição dos subúrbios citadinos da capital. Trata-se de um fenómeno de extensão espacial da ocupação humana e de concentração de povoamento, tanto à escala da aglomeração como à escala local, que desempenhou um papel estruturante na génese e na consolidação do território metropolitano de Lisboa.

Nas secções seguintes, apreender-se-á como a estrutura de povoamento da aglomeração de Lisboa evoluiu na segunda metade do século xx e como esse particular elemento da sua "morfologia urbana" - no sentido conferido por Maurice Halbwachs (1938) a esta expressão - contribuiu para constituir a metrópole de Lisboa enquanto forma espacial e social. Elegeu-se como escala de observação a freguesia. Como se verá, é uma escala adequada quer para medir o crescimento urbano na aglomeração, quer para identificar como é que os subúrbios citadinos de Lisboa se transformam em subúrbios metropolitanos.

\section{A suburbanização de Lisboa}

Para estabelecer a importância do processo de suburbanização na constituição da metrópole de Lisboa fez-se uso duas medidas amplamente utilizadas na literatura (Champion, 2001). A primeira incide nas taxas de crescimento demográfico evidenciadas tanto pelos subúrbios como pela cidade. Por seu intermédio, a suburbanização é assinalada quando o povoamento dos territórios dos arredores registacrescimento superiorao verificadonacidade.
A segunda obtém-se pela comparação entre a grandeza demográficas da população residente nas coroas suburbanas face ao core urbano. Quando na aglomeração o peso demográfico dos subúrbios é superior ao da cidade, a suburbanização encontrar-se-á em franca consolidação.

De forma articulada, estas duas medidas estabelecem os momentos de arranque e de generalização do processo de suburbanização de Lisboa. O Quadro n. $^{\circ} 1$ apresenta em série a primeira medida, ou seja, a comparação entre taxas de crescimento intercensitárias registadas para a população residente em Lisboa e para aquela residente nos seus concelhos limítrofes.

Em primeiro lugar, as taxas de crescimento demográfico recortam com precisão uma geografia do arranque do processo de suburbanização. Os concelhos que na década de 1930 exibem as taxas de crescimento mais elevadas - e, note-se, superiores às verificadas na cidade de Lisboa - são os que haviam historicamente formado relações mais fortes com a cidade. Os principais núcleos suburbanos dos arredores de Lisboa polarizavam a localização de indústria e facultavam espaços de residência suburbana, nalguns casos, associada à vilegiatura.

Em segundo lugar, e progredindo ao longo dos decénios 1940-50 e 1950-60, constata-se a generalização do processo de suburbanização. Esta condição é atingida na década de 1950 quando todos os concelhos integrando a aglomeração apresentam ritmos de crescimento muito elevados e, regra geral, superiores ao de Lisboa. É o caso dos concelhos de Loures, que no seu território integrava as populosas freguesias de Odivelas, Moscavide e Sacavém, ou de Oeiras, onde os lugares de Algés e da Amadora registavam crescimentos sem precedentes, ou ainda de Almada, onde a freguesia sede de concelho e a Cova da Piedade se constituíam também como subúrbios citadinos de primeira grandeza. 
Quadro n. 1 - Taxas de crescimento demográfico intercensitárias em Lisboa e nos seus subúrbios (1920-1981)

[em percentagem]

\begin{tabular}{|l|c|c|c|c|c|}
\hline Concelhos & $1930-1940$ & $1940-1950$ & $1950-1960$ & $1960-1970$ & $1970-1981$ \\
\hline Lisboa & 17,3 & 12,8 & 2,4 & $-5,2$ & 6,3 \\
\hline Cascais & 29,3 & 42,3 & 41,3 & 55,4 & 52,8 \\
\hline Loures* & 20,5 & 43,9 & 102,5 & 63,1 & 66,0 \\
\hline Oeiras** & 28,4 & 40,8 & 77,0 & 91,2 & $-17,1$ \\
\hline Sintra & 18,9 & 33,8 & 32,3 & 55,6 & 82,0 \\
\hline Amadora*** & 41,8 & 92,5 & 152 & 137 & 46 \\
\hline V. F. Xira & 17,6 & 15,7 & 24,0 & 34,2 & 61,9 \\
\hline Alcochete & $\mathbf{0 , 0}$ & 18,1 & 17,9 & 12,3 & 8,0 \\
\hline Almada & 24,7 & 48,1 & 62,1 & 51,6 & 37,3 \\
\hline Barreiro & 24,1 & 13,8 & 18,1 & 68,3 & 49,1 \\
\hline Moita & 30,6 & 57,2 & 49,6 & 33,1 & 37,4 \\
\hline Montijo & 19,3 & 46,4 & 16,7 & 39,6 & $-12,6$ \\
\hline Seixal & 28,2 & 23,2 & 28,4 & 86,1 & 134,1 \\
\hline
\end{tabular}

Fonte: INE, Recenseamentos Gerais da População, 1960 e 1981.

* Inclui a antiga freguesia de Odivelas que veio a dar origem ao concelho com o mesmo nome em 1998.

** Inclui a antiga freguesia da Amadora que veio a dar origem ao concelho com o mesmo nome em 1979. Daí a taxa de crescimento negativa no decénio 1970-1981.

*** Freguesia criada em 1916, integrando o concelho de Oeiras até 1979.

Em terceiro lugar, a intensidade da suburbanização da capital portuguesa fica bem patente no decénio 1960-70. A inflexão que se verifica no sentido do crescimento demográfico de Lisboa $(-5,2 \%)$ ocorre quando a população de Cascais, de Oeiras, de Sintra, de Loures, de Almada, do Barreiro e do Seixal cresce a taxas superiores a 50\%. Observa-se assim o carácter contínuo do processo, bem como os tempos e os ritmos ao longo dos quais se reforçou a estrutura do povoamento suburbano de Lisboa.

A segunda medida da suburbanização coloca em confronto as grandezas demográficas da população residente em Lisboa e daquela residente nos seus arredores face ao total demográfico da aglomeração. No Gráfico n. ${ }^{\circ} 1$ encontra-se bem evidente o recorte produzido pelo confronto entre estas duas proporções, a cada ano censitário, ao longo de mais de cento e cinquenta anos.

Os anos em que Lisboa se urbaniza surgem bem identificados no arco temporal 1864-1940. Como bem demonstra Vítor Matias Ferreira (1987: 85-6-7), a concentração populacional no território da capital tendia à época a ocorrer numa área restrita do concelho. A frente urbana de Lisboa estava ainda longe de atingir o limite administrativo do concelho e os arrabaldes ofereciam um vasto fundo de "terrenos expectantes"(Ferreira, 1994: 154).

\section{Gráfico n. ${ }^{\circ} 1$ - Peso de Lisboa e dos seus concelhos limítrofes na população da Aglomeração de Lisboa (1864-2001)}

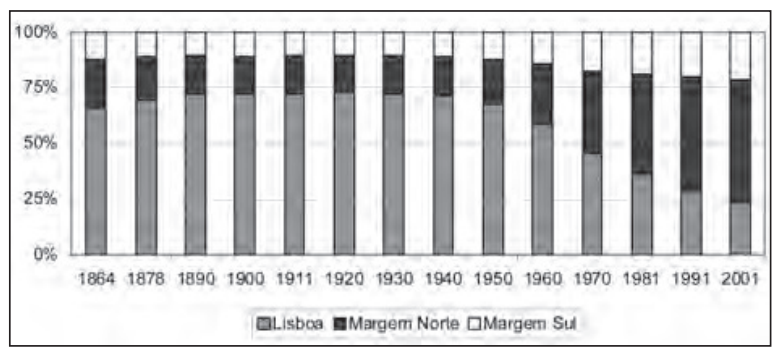

Fonte: INE, Recenseamentos Gerais da População, 1960, 1970, 1981 e 2001

* Margem Norte: Cascais, Sintra, Oeiras, Amadora, Odivelas, Loures e Vila Franca de Xira

** Margem Sul: Alcochete, Montijo, Barreiro, Moita, Seixal e Almada

A partir de 1940, a posição demográfica da cidade de Lisboa na aglomeração altera-se. Primeiro, o seu peso na estrutura urbana da aglomeração decresce ligeiramente e, concomitantemente, o peso dos seus concelhos limítrofes sobe. Porém, Lisboa mantém ainda a dominância demográfica face aos concelhos limítrofes, pois na capital reside mais metade da população recenseada na aglomeração. Depois, entre 1960 e 1970, os concelhos da margem 
norte e da margem sul do Tejo atingem somados mais de metade da população residente no emergente território metropolitano. Daí em diante, o peso do concelho de Lisboa será sempre decrescente mesmo quando, excepcionalmente, no ano de 1981, devido ao retorno das ex-colónias a cidade recupera população e atinge um nível demográfico absoluto ligeiramente superior ao registado em 1960. Todavia, o seu peso relativo na estrutura de povoamento da metrópole é agora bem mais reduzido.

Em 1991, a suburbanização de Lisboa havia já constituído demograficamente os arredores de Lisboa como território metropolitano. A estrutura de povoamento da metrópole era já largamente favorável aos concelhos limítrofes e circunvizinhos à capital. Na margem norte do Tejo residia metade da população da metrópole de Lisboa e a proporção residente na margem sul do Tejo representava um quinto do total da aglomeração. Contas feitas, a população residente nos treze concelhos em redor de Lisboa situava-se acima dos dois terços do todo demográfico metropolitano. Volvidos dez anos, a estrutura do povoamento da metrópole evidencia ainda mais o domínio demográfico dos subúrbios metropolitanos de Lisboa. É num conjunto de treze concelhos circunvizinhos à capital que no ano de 2001 residem três quartos da população da aglomeração.

As duas medidas permitem situar a cidade de Lisboa e seus arredores na tendência de crescimento das cidades ocidentais, na qual, de acordo com Tony Champion (2001: 150), a suburbanização constituiu o "processo dominante" de redistribuição populacional após a Segunda Guerra Mundial.

\section{A morfogénese da metrópole de Lisboa}

Uma das principais marcas da constituição de um território com características metropolitanas é a transposição do limiar populacional do primeiro milhão habitantes (Bassand, 1997). No caso de Lisboa, como bem evidencia o Gráfico n. ${ }^{\circ}$, o povoamento dos subúrbios é um contributo fundamental para que tal marco morfológico e analítico seja atingido. É por seu intermédio que a aglomeração de Lisboa ultrapassa a fasquia do primeiro milhão de habitantes (1960) e que, sublinhe-se, vinte anos depois o limiar do segundo milhão de habitantes (1981) será superado. No lapso de duas décadas, os subúrbios da Lisboa registam um crescimento quasi-milionário e fortemente polarizado pelos concelhos situados a norte do Tejo (Gráfico n. ${ }^{\circ}$ 2).

Gráfico n. 2 - Evolução dos volumes de população em Lisboa e seus concelhos limítrofes (1940-2001)

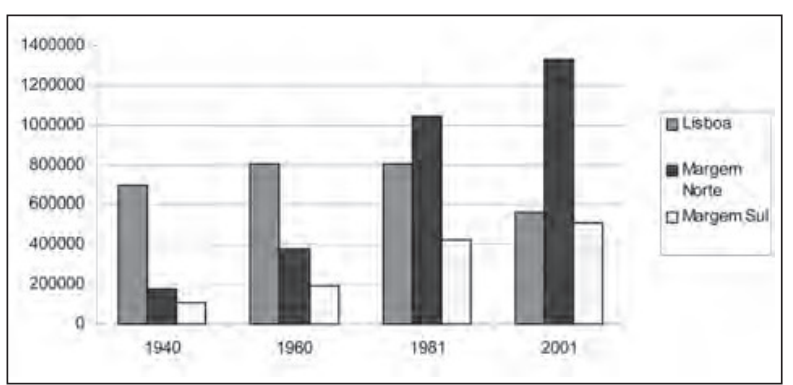

Fonte: INE, Recenseamentos Gerais da População, 1960, 1981 e 2001

* Margem Norte: Cascais, Sintra, Oeiras, Amadora, Odivelas, Loures e Vila Franca de Xira

** Margem Sul: Alcochete, Montijo, Barreiro, Moita, Seixal e Almada

Desagregando a escala de análise territorial, verifica-se que a concentração demográfica se deve sobretudo à rapidez do crescimento do volume populacional dos concelhos envolventes à capital. Entre 1940 e 1960, a população dos concelhos situados na margem norte do Tejo duplica, passando de 175 mil para 375 mil habitantes. Entre 1960 e 1991, triplica e perfaz mais de um milhão de habitantes. Em 2001, residia nos concelhos situados na margem norte do Tejo uma população sete vezes superior à que se registava em 1940 - isto é, um milhão e trezentos mil habitantes. Quanto à margem sul do Tejo, os volumes populacionais são de menor grandeza, mas, ainda assim, revelam um constante e significativo crescimento. Este conjunto de concelhos cresce de 105 mil habitantes em 1940 para 194 mil habitantes em 1960. Nos três decénios seguintes, a sua população mais que duplica, situando-se então na ordem das quatro centenas de milhar de habitantes. No ano de 2001, nos concelhos a sul do Tejo residiam quinhentas e nove mil pessoas - uma população cinco vezes superior ao número de habitantes registado em 1940.

Tem especial significado no processo de constituição metropolitana da capital o facto de Lisboa se inscrever num curso de perda de população. Iniciada na década de 60 e a um ritmo lento, essa perda foi compensada com o fluxo de população que retornou das antigas colónias após a Revolu- 
ção de Abril de 1974. Todavia, essa inversão no sentido negativo do crescimento - que, como se viu, se observa no ano de 1981 e que culmina num máximo demográfico absoluto - desvanece-se perante a escala demográfica atingida pelos concelhos limítrofes. Nas duas últimas décadas do século $\mathrm{xx}$, a perda de população do concelho de Lisboa fica bem expressa no facto de no ano de 2001 aí residir um contingente populacional na ordem das quinhentas e sessenta e cinco mil pessoas - um valor que representa quatro quintos da população residente na cidade no ano de 1940 e quando a área edificada era comparativamente mais reduzida.

\section{Exploração de um indicador de concentração populacional metropolitana}

Uma imagem mais detalhada da morfogénese da metrópole de Lisboa é obtida através da análise à evolução da concentração do povoamento tendo como indicador ção residente por freguesia. Através de um estatístico construído para o efeito, analisou-se aquele fenómeno, procurando identificar os daquele mesmo processo. Três operações de cálculo encontram-se na base deste dispositivo de medida de concentração: em primeiro lugar, calculou-se o valor em percentagem da população residente em cada unidade, neste caso, cada freguesia, face ao total da população registada, em cada ano censitário, na aglomeração; em segundo lugar, realizou-se a ordenação decrescente desses valores enquanto frequência simples; e, em terceiro lugar, calculou-se a frequência acumulada que foi ordenada decrescentemente e repartida em quartis. $\mathrm{O}$ resultado é uma distribuição ordenada das freguesias que compõem o território de Lisboa e dos seus concelhos limítrofes, encimada pela freguesia que a cada ano mais contribui demo- graficamente para a estrutura de povoamento da aglomeração. Em cada distribuição, que se apresenta em tabela, as freguesias surgem ordenadas pelo seu contributorelativona estrutura de povoamento e associadas ao seu contributo acumulado. $\mathrm{O}$ dispositivo foi aplicado aos dados dos Recenseamentos Gerais da População realizados nos anos de 1940, 1960, 1981 e 2001 e daí resultaram quatro imagens da concentração populacional no território constituído por Lisboa e pelos seus treze concelhos vizinhos. ${ }^{1}$

\section{A Grande Lisboa (1940)}

Em 1940, nas oitenta e nove freguesias que compunham o território de Lisboa e dos seus concelhos limítrofes residiam cerca de 969 mil pessoas. Um quarto desta população habitava em quatro freguesias: São Sebastião da Pedreira, que liderava a distribuição com 78 mil habitantes e onde se concentrava $8 \%$ da população neste território, e o trio formado por Santa Isabel, São Jorge de Arroios e Penha de França. Outro quarto habitava em onze freguesias e neste grupo apenas uma não integrava o perímetro administrativo da capital - o Barreiro. É marcante o facto de aproximadamente meio milhão de habitantes residir em catorze freguesias situadas no interior e na envolvente à Lisboa histórica no grande subúrbio industrial que era o Barreiro.No terceiro quartil da distribuição situavam-se os principais núcleos suburbanos de Lisboa, representados pelas sede de concelho e pela Amadora, pela Cova da Piedade e por Carnaxide. Esta última freguesia, cuja sede se localizava à época em pleno arrabalde de Oeiras, alojava o populoso lugar de Algés. Cômputo geral, três quartos dos 969 mil habitantes de Lisboa e seus concelhos limítrofes residiam em apenas trinta e cinco freguesias num território formado por oitenta e nove destas unidades (Quadro n. ${ }^{\circ}$ 2).

\footnotetext{
${ }^{1}$ Ao longo de todo o texto, o território em análise é composto pelos concelhos de Lisboa, Cascais, Sintra, Oeiras, Amadora, Odivelas, Loures e Vila Franca de Xira, Alcochete, Montijo, Barreiro, Moita, Seixal e Almada e consequentemente pelas freguesias que ao longo do tempo (1940-1960) integram a sua circunscrição administrativa.
} 
Quadro n. 2 - Concentração demográfica em Lisboa e nos seus concelhos limítrofes em 1940

\begin{tabular}{|c|c|c|c|}
\hline Freguesia & População & Peso Relativo (\%) & Peso Acumulado (\%) \\
\hline São Sebastião da Pedreira & 78838 & 8,1 & \\
\hline Santa Isabel & 67535 & 7,0 & 15,1 \\
\hline São Jorge de Arroios & 49498 & 5,1 & 20,2 \\
\hline Penha de França & 38455 & 4,0 & 24,2 \\
\hline Santa Engrácia & 37405 & 3,9 & 28,0 \\
\hline Anjos & 35152 & 3,6 & 31,7 \\
\hline Alcântara & 33747 & 3,5 & 35,1 \\
\hline Ajuda & 28340 & 2,9 & 38,1 \\
\hline Santos-o-Velho & 25224 & 2,6 & 40,7 \\
\hline Coração de Jesus & 21973 & 2,3 & 42,9 \\
\hline Barreiro & 19983 & 2,1 & 45,0 \\
\hline Santa Maria dos Olivais & 18210 & 1,9 & 46,9 \\
\hline Santa Maria de Belém & 17435 & 1,8 & 48,7 \\
\hline Beato & 16949 & 1,8 & 50,4 \\
\hline Pena & 15595 & 1,6 & 52,0 \\
\hline Lapa & 15508 & 1,6 & 53,6 \\
\hline Carnaxide & 15345 & 1,6 & 55,2 \\
\hline São Mamede & 14875 & 1,5 & 56,7 \\
\hline Benfica & 13905 & 1,4 & 58,2 \\
\hline Santa Catarina & 13778 & 1,4 & 59,6 \\
\hline Mercês & 13606 & 1,4 & 61,0 \\
\hline Montijo & 12287 & 1,3 & 62,3 \\
\hline Encarnação & 11388 & 1,2 & 63,5 \\
\hline Almada & 10755 & 1,1 & 64,6 \\
\hline Lumiar & 10634 & 1,1 & 65,7 \\
\hline São José & 10565 & 1,1 & 66,7 \\
\hline Vila Franca de Xira & 10305 & 1,1 & 67,8 \\
\hline Socorro & 10239 & 1,1 & 68,9 \\
\hline Amadora & 9762 & 1,0 & 69,9 \\
\hline São Vicente de Fora & 9280 & 1,0 & 70,8 \\
\hline Campo Grande & 9122 & 0,9 & 71,8 \\
\hline Cascais & 8549 & 0,9 & 72,7 \\
\hline São Domingos de Rana & 8315 & 0,9 & 73,5 \\
\hline São Paulo & 8068 & 0,8 & 74,3 \\
\hline Cova da Piedade & 7722 & $\mathbf{0 , 8}$ & 75,1 \\
\hline \multicolumn{4}{|l|}{ 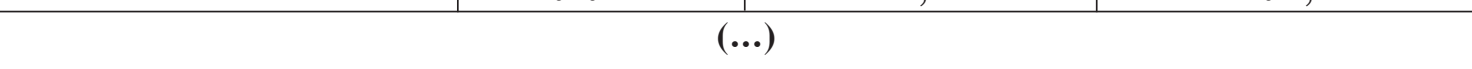 } \\
\hline
\end{tabular}

Fonte: INE, Recenseamentos Gerais da População, 1960. 
Compactação é o termo que melhor convém à imagem demográfica e urbana de Lisboa e dos seus subúrbios no ano de 1940. Esta propriedade da estrutura de povoamento e de ocupação do território traduzia-se tanto na grande cidade de Lisboa como nos seus subúrbios citadinos. Por um lado, Lisboa afirmava-se face ao território envolvente como uma grande cidade. A sua ocupação era densa, em actividades e em alojamento, e a cidade concentrava funções que emprestavam a certas zonas a forma de ocupação típica dos "centros urbanos" (Castells, 1984). Por outro lado, em seu redor e face a um imenso fundo de quintas e de campos situavam-se os seus núcleos suburbanos cuja posição urbana era variável.

Nalguns casos, a sua posição era arrabaldina, enfrentando a frente urbana da cidade de Lisboa que desde o início do século XX progredia na conquista das quintas e dos campos em seu redor (Baptista, 1994). Na distribuição, as freguesias de Santa Maria dos Olivais, do Beato, da Ajuda ou de Benfica, bem como as formas de crescimento urbano presentes ao longo das estradas de entrada e saída da cidade, denotam esta condição morfológica. Como bem sublinha Raquel Soeiro de Brito (1976), esta era uma condição desde cedo ocultada pela reconversão urbana de que foram sendo objecto estes e outros territórios suburbanos.

Noutros casos, os subúrbios citadinos de Lisboa constituíam-se como bastião urbano, reunindo alojamento e uma oferta de serviços citadinos, quantitativa e qualitativamente variáveis. Encontravam-se geralmente bem conectados à cidade através de transporte colectivo, sobretudo os "subúrbios de "porta" (Salgueiro, 2001: 44). As descrições da época relativas à Amadora dão justamente conta de uma particular constelação de edificado e de populações, de actividades e de instituições urbanas locais - como o correio e o telégrafo, as indústrias e os comércios, as escolas, as associações ou as cooperativas de consumo - que, articuladamente, conferiam um carácter citadino, à la fois residencial e industrial, àquele subúrbio (Nunes, 2007: 133-8).

\section{A emergência da Metrópole de Lisboa (1960)}

Para o ano de 1960, a imagem da concentração demográfica e da estrutura de povoamento da urbe que se obtém a partir do XI Recenseamento Geral da População dá a conhecer uma grande cidade que em seu redor polarizava subúrbios citadinos com dimensão considerável. Tal como acima se deixou expresso, em 1960, o limiar demográfico do primeiro milhão de habitantes é ultrapassado. Se aos cerca de 802 mil habitantes da capital se somarem aqueles que residem nos principais núcleos suburbanos, recorta-se com nitidez uma imagem da então embrionária metrópole de Lisboa.

Observe-se a distribuição apresentada no Quadro n. ${ }^{\circ}$ 3. No topo da distribuição ressalta desde logo um dado importante: a mais populosa freguesia é a Amadora, registando à data cerca de $47 \mathrm{mil}$ habitantes, o quíntuplo dos 9700 habitantes que aí residiam em 1940. Seguem-se-lhe, no concelho de Lisboa, São Jorge de Arroios, Santo Contestável, Nossa Senhora de Fátima, Campolide, São João, Alcântara e Penha de França, e, nos arredores, Almada e Carnaxide. Nestas dez freguesias residem trezentas e cinquenta e três mil pessoas, um quarto do um milhão e quatrocentos mil habitantes que povoam as cento e vinte e duas freguesias que compõem o território da aglomeração.

Relativamente ao segundo quartil da distribuição, as quinze freguesias aí posicionadas confirmam o crescente relevo demográfico e urbano dos territórios suburbanos da capital. Encimando o segundo quartil da distribuição está Odivelas, uma outra freguesia contígua a Lisboa. Em 1940, Odivelas estava posicionada no quarto quartil da distribuição e aí residiam cerca de 3900 pessoas, vinte anos depois encontra-se à beira do primeiro quartil, alojando 27400 pessoas. Fora do perímetro administrativo da capital, seguem-se-lhe a Cova da Piedade, o Barreiro, Moscavide e o Montijo. Por fim, no terceiro quartil da distribuição, entre as vinte e três freguesias aí posicionadas, encontram-se algumas cuja condição suburbana evidenciava já um considerável peso demográfico. Eram, à época, as frentes avançadas da urbanização dos arredores da capital - Alhos Vedros, Queluz, Cascais e Alcabideche e Sacavém. Contas feitas, metade da população residente na metrópole em constituição, cerca de 685 mil pessoas, residia em apenas vinte e cinco freguesias, oito das quais em concelhos vizinhos à capital, num território formado por cento e vinte e duas destas unidades. 
Quadro n. 3 - Concentração demográfica em Lisboa e nos seus concelhos limítrofes em 1960

\begin{tabular}{|c|c|c|c|}
\hline Freguesia & População & Peso Relativo \% & Peso Acumulado \% \\
\hline Amadora & 47355 & 3,4 & \\
\hline São Jorge de Arroios & 46506 & 3,4 & 6,8 \\
\hline Santo Contestável & 39199 & 2,9 & 9,7 \\
\hline Nossa Senhora de Fátima & 35262 & 2,6 & 12,3 \\
\hline Campolide & 33764 & 2,5 & 14,7 \\
\hline São João & 32466 & 2,4 & 17,1 \\
\hline Almada & 31523 & 2,3 & 19,4 \\
\hline Alcântara & 30625 & 2,2 & 21,6 \\
\hline Penha de França & 28420 & 2,1 & 23,7 \\
\hline Carnaxide & 28301 & 2,1 & 25,7 \\
\hline Odivelas & 27423 & 2,0 & 27,7 \\
\hline São João de Deus & 24943 & 1,8 & 29,6 \\
\hline Ajuda & 24541 & 1,8 & 31,3 \\
\hline Cova da Piedade & 23585 & 1,7 & 33,1 \\
\hline Anjos & 23572 & 1,7 & 34,8 \\
\hline Barreiro & 23433 & 1,7 & 36,5 \\
\hline Benfica & 23161 & 1,7 & 38,2 \\
\hline Moscavide & 22065 & 1,6 & 39,8 \\
\hline Montijo & 21947 & 1,6 & 41,4 \\
\hline Santa Maria de Belém & 20416 & 1,5 & 42,9 \\
\hline Prazeres & 20326 & 1,5 & 44,3 \\
\hline São Domingos de Benfica & 20137 & 1,5 & 45,8 \\
\hline Beato & 20129 & 1,5 & 47,3 \\
\hline São João de Brito & 20073 & 1,5 & 48,7 \\
\hline Marvila & 20001 & 1,5 & 50,2 \\
\hline Alhos Vedros & 19606 & 1,4 & 51,6 \\
\hline Lapa & 19464 & 1,4 & 53,0 \\
\hline Campo Grande & 18900 & 1,4 & 54,4 \\
\hline São Sebastião da Pedreira & 17259 & 1,3 & 55,7 \\
\hline Alvalade & 16619 & 1,2 & 56,9 \\
\hline Queluz & 15746 & 1,1 & 58,0 \\
\hline Graça & 15122 & 1,1 & 59,1 \\
\hline Pena & 14980 & 1,1 & 60,2 \\
\hline Coração de Jesus & 14974 & 1,1 & 61,3 \\
\hline Santa Isabel & 14950 & 1,1 & 62,4 \\
\hline São Mamede & 13888 & 1,0 & 63,4 \\
\hline Santos-o-Velho & 13788 & 1,0 & 64,4 \\
\hline Mercês & 13558 & 1,0 & 65,4 \\
\hline Vila Franca de Xira & 13404 & 1,0 & 66,4 \\
\hline Cascais & 13352 & 1,0 & 67,4 \\
\hline Alcabideche & 12725 & 0,9 & 68,3 \\
\hline Alto do Pina & 12570 & 0,9 & 69,2 \\
\hline Santa Maria dos Olivais & 11896 & 0,9 & 70,1 \\
\hline Santa Engrácia & 11748 & 0,9 & 70,9 \\
\hline Santa Catarina & 11715 & 0,9 & 71,8 \\
\hline São Vicente de Fora & 11533 & 0,8 & 72,6 \\
\hline Estoril & 11193 & 0,8 & 73,4 \\
\hline São José & 10856 & 0,8 & 74,2 \\
\hline Sacavém & 10624 & $\mathbf{0 , 8}$ & 75,0 \\
\hline \multicolumn{4}{|c|}{$(\ldots)$} \\
\hline
\end{tabular}

Fonte: INE, Recenseamentos Gerais da População, 1960. 
O confronto entre as distribuições relativas aos anos de 1940 e 1960 é esclarecedor. O povoamento dos subúrbios citadinos de Lisboa, sobretudo daqueles mais penetrantes no hinterland da capital, atingia já considerável peso. À antiga posição de bastião urbano encontravam-se agora adstritas novas "formas de crescimento urbano" (Sola Morales, 1997) como os grandes conjuntos residenciais ou como as "urbanizações marginais", variavelmente precárias e, por vezes, marcadas pela ilegalidade de loteamento e construção. A sua grandeza demográfica encontrava-se então intimamente relacionada com o transporte colectivo, elemento organizador dos eixos de comunicação urbano-metropolitanos (Ferreira 1987: 237). É justamente no final da década de 50 que tanto a linha de Azambuja como a linha de Sintra são electrificadas (Moura e Gomes, 1999). À mudança na maquinaria e nos horários corresponderá a emergência de novos destinos residenciais e a disseminação do commuting, reforçando o peso e a posição suburbana de novos espaços residenciais, de que a Damaia (Nunes, 2007: 182-6) ou Queluz (Salgueiro, 2001:44) constituem exemplos. A importância do transporte colectivo na urbanização e suburbanização dos arredores de Lisboa não se esgotava no caminho-de-ferro, como, aliás, bem estabelecem os estudos preparatórios do Plano Director da Região de Lisboa. À via-férrea juntavam-se as linhas de camionagem e as travessias fluviais do Tejo, ambas organizando caudais que reforçavam o papel da baixa de Lisboa como placa giratória nos percursos casa-trabalho (MOP, 1964). Lisboa era então uma grande cidade polarizando subúrbios citadinos em crescimento.

\section{A consolidação metropolitana (1981)}

Para a distribuição relativa ao ano de 1981 é necessário mobilizar uma escala de leitura vincadamente metropolitana: quer pela dimensão demográfica das freguesias que lideram a distribuição, quer pela disposição territorial da concentração do povoamento que se aí encontra patente, quer ainda, e em especial, pelo facto de neste território residirem aproximadamente 2 milhões e 280 mil pessoas, um acréscimo, como se viu, de cerca 960 mil habitantes face ao ano de 1960. No lapso de duas décadas, Lisboa e os seus territórios vizinhos ultrapassam o limiar do segundo milhão de habitantes. Globalmente, para o ano de 1981, tem-se que no concelho de Lisboa residam cerca de 807 mil pessoas. Os concelhos da margem norte do Tejo atingiam um volume próximo do um milhão e quarenta e cinco mil habitantes e os da margem sul, quatrocentos e vinte e seis mil habitantes. Um novo concelho é criado, o concelho da Amadora. A quase totalidade do seu território é originária da antiga freguesia, anteriormente integrada na circunscrição administrativa de Oeiras. Organizado em oito freguesias, o novo concelho altera significativamente a distribuição que se tem vindo a analisar. Com 163 mil habitantes no ano de 1981, o concelho da Amadora reunia 7,1\% da distribuição demográfica que se tem vindo a trabalhar. Ao estabelecer-se como unidade a freguesia, a população da Amadora fica fraccionada em oito unidades, desfazendo-se um importante elemento da imagem dos subúrbios metropolitanos de Lisboa.

O território em análise era então composto por cento e trinta e três freguesias e um quarto da população residente concentrava-se em dez freguesias onde se alojavam 568 mil habitantes (Quadro n. ${ }^{\circ}$ 4) A comandar a ordenação encontrava-se a freguesia de Odivelas, com cerca de 80 mil habitantes, mais 53 mil habitantes do que em 1960. As restantes nove freguesias situadas no primeiro quartil eram Carnaxide, Cova da Piedade, Santa Maria dos Olivais, Benfica, Agualva-Cacém, Queluz, Barreiro, Almada e Marvila. É de sublinhar que as três freguesias de Lisboa que se situam neste segmento da distribuição - Santa Maria dos Olivais, Benfica e Marvila - totalizam aproximadamente $150 \mathrm{mil}$ habitantes e representam $19 \%$ por cento da população da capital em 1981.

Nas dezanove freguesias que integram o segundo quartil da distribuição sobressaem aquelas que denotam a ocupação de territórios cada vez mais longínquos da capital. São territórios que adquirem posição significativa na estrutura de povoamento da metrópole e que alojam contingentes populacionais na ordem das três dezenas de milhar de habitantes. É por exemplo o caso de Algueirão-Mem Martins, de Cascais, de São Domingos de Rana, de Oeiras e de Loures, a norte do Tejo, da Amora, de Corroios e da Baixa da Banheira, a sul do Tejo. 
Quadro n. 4 - Concentração demográfica em Lisboa e nos seus concelhos limítrofes em 1981

\begin{tabular}{|c|c|c|c|}
\hline Freguesia & População & Peso Relativo \% & Peso Acumulado \% \\
\hline Odivelas (Lumiar e Carnide) & 84624 & 3,7 & \\
\hline Carnaxide & 78583 & 3,5 & 7,16 \\
\hline Cova da Piedade & 64953 & 2,9 & 10,0 \\
\hline Santa Maria dos Olivais & 61941 & 2,7 & 12,7 \\
\hline Benfica & 51586 & 2,3 & 15,0 \\
\hline Agualva-Cacém & 49445 & 2,2 & 17,2 \\
\hline Queluz & 48112 & 2,1 & 19,3 \\
\hline Barreiro & 46251 & 2,0 & 21,3 \\
\hline Almada & 42684 & 1,9 & 23,2 \\
\hline Marvila & 40689 & 1,8 & 25,0 \\
\hline Oeiras (e São Julião da Barra) & 40358 & 1,8 & 26,7 \\
\hline São Domingos de Benfica & 39209 & 1,7 & 28,4 \\
\hline Algueirão Mem-Martins & 35312 & 1,6 & 30,0 \\
\hline Amora & 34589 & 1,5 & 31,5 \\
\hline São Jorge de Arroios & 33610 & 1,5 & 33,0 \\
\hline Loures & 32874 & 1,4 & 34,4 \\
\hline Falagueira-Venda Nova & 32759 & 1,4 & 35,9 \\
\hline Lumiar & 29645 & 1,3 & 37,2 \\
\hline Santo Contestável & 29612 & 1,3 & 38,5 \\
\hline Cascais & 29389 & 1,3 & 39,7 \\
\hline São Domingos de Rana & 29342 & 1,3 & 41,0 \\
\hline Baixa da Banheira & 28780 & 1,3 & 42,3 \\
\hline Mina & 28427 & 1,3 & 43,5 \\
\hline Sacavém & 27945 & 1,2 & 44,8 \\
\hline Ajuda & 27664 & 1,2 & 46,0 \\
\hline Montijo & 27257 & 1,2 & 47,2 \\
\hline Campolide & 26655 & 1,2 & 48,3 \\
\hline Nossa Senhora de Fátima & 26437 & 1,2 & 49,5 \\
\hline Corroios & 25499 & 1,1 & 50,6 \\
\hline Alcabideche & 25473 & 1,1 & 51,7 \\
\hline São João & 24889 & 1,1 & 52,8 \\
\hline Moscavide & 24390 & 1,1 & 53,9 \\
\hline Estoril & 24312 & 1,1 & 55,0 \\
\hline Alverca do Ribatejo & 24092 & 1,1 & 56,0 \\
\hline Caparica & 23620 & 1,0 & 57,1 \\
\hline Damaia & 23261 & 1,0 & 58,1 \\
\hline Venteira & 23207 & 1,0 & 59,1 \\
\hline Brandoa & 22968 & 1,0 & 60,1 \\
\hline Penha de França & 22772 & 1,0 & 61,1 \\
\hline Alcântara & 22697 & 1,0 & 62,1 \\
\hline Rio de Mouro & 22597 & 1,0 & 63,1 \\
\hline São João de Brito & 20728 & 1,0 & 64,0 \\
\hline Beato & 20718 & 1,0 & 64,9 \\
\hline Parede & 20094 & 0,9 & 65,8 \\
\hline Camarate & 19900 & 0,9 & 66,7 \\
\hline Paço de Arcos & 19645 & 0,9 & 67,5 \\
\hline Póvoa de Santo Adrião & 19386 & 0,9 & 68,4 \\
\hline Vila Franca de Xira & 19318 & 0,9 & 69,2 \\
\hline Arrentela & 18765 & 0,8 & 70,0 \\
\hline Anjos & 18283 & 0,8 & 70,8 \\
\hline São João da Talha & 18273 & 0,8 & 71,7 \\
\hline Lavradio & 18252 & 0,8 & 72,5 \\
\hline Vialonga & 17922 & 0,8 & 73,2 \\
\hline São João de Deus & 17912 & 0,8 & 74,0 \\
\hline Santa Maria de Belém & 17057 & 0,8 & 74,8 \\
\hline Belas & 16838 & 0,7 & 75,5 \\
\hline
\end{tabular}

Fonte: INE, Recenseamentos Gerais da População, 1981. 
Numericamente, metade da população residente na metrópole de Lisboa - um milhão e cento e quarenta mil pessoas - concentrava-se em vinte e nove freguesias, num território formado por cento e trinta e três destas unidades.

Um significativo indício do carácter metropolitano da concentração do povoamento evidencia-se no facto de algumas das mais populosas freguesias da metrópole de Lisboa serem unidades administrativas de criação recente. Territórios que até há bem pouco tempo eram um arrabalde de núcleos suburbanos mais antigos apresentavam agora características de povoamento cuja saliência demográfica e urbana requeria do poder político democrático recém-instituído tradução em termos de estrutura político-administrativa. A explosiva urbanização dos arredores e dos subúrbios citadinos de Lisboa de então encontra-se bem expressa no curso demográfico e urbano da freguesia da Agualva-Cacém. Em 1960, naquela freguesia alojavam-se cerca de 7 mil habitantes e em 1981 eram recenseados 45 mil habitantes. Aliás, o carácter metropolitano da concentração demográfica e da estrutura de povoamento não se evidencia apenas na escala do crescimento, nem na grandeza das freguesias. Fica igualmente bem traduzido na constituição de corredores de expansão urbana.

\section{Lisboa Metrópole (2001)}

Para o ano de 2001, a imagem da concentração populacional na metrópole de Lisboa obtida é ainda mais polarizada pelos subúrbios metropolitanos. Nas cento e setenta e quatro freguesias que compõem o território que se tem vindo a analisar residiam cerca de dois milhões e quatrocentas mil pessoas. Um quarto desta população concentra-se em treze freguesias (Quadro n. ${ }^{\circ}$ 5). A mais populosa freguesia da metrópole de Lisboa é Agualva-Cacém, com cerca de 81 mil habitantes. Juntam-se-lhe, no primeiro quartil da distribuição, Algueirão MemMartins, Odivelas, Amora, Corroios, Santa Maria dos Olivais, Rio de Mouro, São Domingos de Rana, Benfica, Marvila, Lumiar, Oeiras e São Domingos de Benfica. Nestas treze freguesias residem 618 mil pessoas. Adicionando-lhes as vinte e cinco freguesias que se agrupam no segundo quartil da distribuição, e os 618 mil habitantes que aí residiam em 2001, resulta evidente uma interessante propriedade da composição metropolitana da maior cidade portuguesa: é ao longo das principais linhas férreas- linha de Sintra, Cascais, Azambuja e Sul do Tejo - e principais rodovias - Al e A2, A5 e A8, Segunda Circular e Eixo Norte Sul, CRIL e CREL - e num território constituído por trinta e oito freguesias que se concentra metade da população da metrópole, cerca de um milhão e 200 mil habitantes (Quadro n. ${ }^{\circ}$ 5).

De entre estas trinta e oito freguesias, apenas pertencem à circunscrição administrativa de Lisboa - Santa Maria dos Olivais, Benfica, Marvila, Lumiar e São Domingos de Benfica - e situam-se no primeiro quartil da distribuição. Compreendem no seu interior os lugares do crescimento urbano que ocorreu na capital nos últimos quarenta anos. A sua posição mostra como o crescimento foi progressivamente atingindo o limite administrativo do concelho e como a contiguidade e a continuidade do edificado foram atingidas. Somente no terceiro quartil se encontram outras freguesias alfacinhas. A ausência de freguesias lisboetas no segundo quartil da distribuição expressa bem a consolidação da estrutura de povoamento da metrópole e a grandeza das unidades que compõem os seus mais populosos territórios. São subúrbios metropolitanos. Atingiram, tanto na margem norte quanto na margem sul do Tejo, um grau de concentração populacional assinalável. São lugares marcados por uma acentuada pluralidade territorial - fazendo uso da sagaz conceptualização de Jean-Marc Stébé (1999). Vistos a partir do seu interior, compreendem uma assinalável diversidade morfológica, desde a sua composição social à acessibilidade, passando pelas actividades económicas e pelo grau de especialização residencial. Vistos em conjunto, numa apreensão global à escala da aglomeração, são reveladores da diferenciação socioespacial da metrópole. 
Quadro n. 5 - Concentração demográfica em Lisboa e nos seus concelhos limítrofes em 2001

\begin{tabular}{|c|c|c|c|}
\hline Freguesia & Populaçãao & Peso Relativo \% & Peso Acumulado \% \\
\hline Agualva-Cacém & 81845 & 3,4 & \\
\hline Algueirão Mem-Martins & 62557 & 2,6 & 6 \\
\hline Odivelas (Lumiar e Carnide) & 53449 & 2,2 & 8,2 \\
\hline Amora & 50991 & 2,1 & 10,4 \\
\hline Corroios & 46475 & 1,9 & 12,3 \\
\hline Santa Maria dos Olivais & 46410 & 1,9 & 14,2 \\
\hline Rio de Mouro & 46022 & 1,9 & 16,1 \\
\hline São Domingos de Rana & 43991 & 1,8 & 18 \\
\hline Benfica & 41368 & 1,7 & 19,7 \\
\hline Marvila & 38767 & 1,6 & 21,3 \\
\hline Lumiar & 37693 & 1,6 & 22,9 \\
\hline Oeiras (e São Julião da Barra) & 34851 & 1,5 & 24,3 \\
\hline São Domingos de Benfica & 33678 & 1,4 & 25,7 \\
\hline Cascais & 33255 & 1,4 & 27,1 \\
\hline Alcabideche & 31801 & 1,3 & 28,4 \\
\hline Alverca do Ribatejo & 29086 & 1,2 & 29,6 \\
\hline Arrentela & 28609 & 1,2 & 30,8 \\
\hline Massamá & 28176 & 1,2 & 32 \\
\hline Queluz & 27913 & 1,2 & 33,2 \\
\hline Póvoa de Santa Iria & 24277 & 1,0 & 34,2 \\
\hline Loures & 24237 & 1,0 & 35,2 \\
\hline Pontinha & 24023 & 1,0 & 36,2 \\
\hline Estoril & 23769 & 1,0 & 37,2 \\
\hline Baixa da Banheira & 23712 & 1,0 & 38,2 \\
\hline Paço de Arcos & 23496 & 1,0 & 39,1 \\
\hline Montijo & 22915 & 1,0 & 40,1 \\
\hline Monte Abraão & 22041 & 0,9 & 41 \\
\hline Linda-a-Velha & 21952 & 0,9 & 41,9 \\
\hline Santo António do Cavaleiros & 21947 & 0,9 & 42,8 \\
\hline Carnaxide & 21354 & 0,9 & 43,7 \\
\hline Laranjeiro & 21175 & 0,9 & 44,6 \\
\hline Belas & 21172 & 0,9 & 45,5 \\
\hline Cova da Piedade & 21154 & 0,9 & 46,4 \\
\hline São Brás & 20694 & 0,9 & 47,2 \\
\hline Damaia & 20590 & 0,9 & 48,1 \\
\hline Alto do Seixalinho & 20522 & 0,9 & 48,9 \\
\hline Charneca de Caparica & 20418 & 0,8 & 49,8 \\
\hline Carcavelos & 20037 & $\mathbf{0 , 8}$ & 50,6 \\
\hline Venteira & 19607 & 0,8 & 51,4 \\
\hline Algés & 19542 & 0,8 & 52,3 \\
\hline Almada & 19513 & 0,8 & 53,1 \\
\hline Caparica & 19327 & 0,8 & 53,9 \\
\hline Carnide & 18989 & 0,8 & 54,7 \\
\hline Mina & 18915 & 0,8 & 55,5 \\
\hline Camarate & 18821 & 0,8 & 56,2 \\
\hline Vila Franca de Xira & 18442 & 0,8 & 57 \\
\hline São João da Talha & 17970 & 0,7 & 57,8 \\
\hline Ajuda & 17958 & 0,7 & 58,5 \\
\hline Parede & 17830 & 0,7 & 59,2 \\
\hline Sacavém & 17659 & 0,7 & 60 \\
\hline Santa Iria da Azoia & 17571 & 0,7 & 60,7 \\
\hline Santo Contestável & 17553 & 0,7 & 61,4 \\
\hline São Jorge de Arroios & 17404 & 0,7 & 62,2 \\
\hline São João & 17073 & 0,7 & 62,9 \\
\hline Moita & 16727 & 0,7 & 63,6 \\
\hline Feijó & 16072 & 0,7 & 64,2 \\
\hline
\end{tabular}




\begin{tabular}{|l|c|c|c|}
\hline Buraca & 16061 & 0,7 & 64,9 \\
\hline Campolide & 15927 & 0,7 & 65,6 \\
\hline Ramada & 15770 & 0,7 & 66,2 \\
\hline Brandoa & 15647 & 0,7 & 66,9 \\
\hline Reboleira & 15543 & 0,6 & 67,5 \\
\hline Vialonga & 15471 & 0,6 & 68,2 \\
\hline Portela & 15441 & 0,6 & 68,8 \\
\hline Nossa Senhora de Fátima & 15291 & 0,6 & 69,4 \\
\hline Póvoa de Santo Adrião & 14704 & 0,6 & 70,1 \\
\hline Alcântara & 14443 & 0,6 & 70,7 \\
\hline Falagueira-Venda Nova & 14436 & 0,6 & 71,3 \\
\hline Alfornelos & 14305 & 0,6 & 71,9 \\
\hline Beato & 14241 & 0,6 & 72,4 \\
\hline Porto Salvo & 13724 & 0,6 & 73 \\
\hline Penha de França & 13722 & 0,6 & 73,6 \\
\hline São João de Brito & 13449 & 0,6 & 74,2 \\
\hline Lavradio & 13051 & 0,5 & $\mathbf{7 5 , 2}$ \\
\hline Alhos Vedros & $\mathbf{1 2 6 1 4}$ & $\mathbf{0 , 5}$ & \\
\hline \multicolumn{2}{|l}{$(\ldots)$} & \\
\hline
\end{tabular}

Fonte: INE, Recenseamentos Gerais da População, 2001

Face ao forte contributo dos subúrbios metropolitanos para a estrutura de povoamento da aglomeração, a posição das freguesias lisboetas na distribuição é marcada por uma considerável tensão morfológica. Por um lado, integram um concelho que evidencia uma forte densidade construtiva, que aloja uma densa rede de transportes e que polariza os segmentos mais elevados da económica da metrópole (Ferrão et al. ). Por outro lado, a elevada densidade do edificado, a conectividade e extensão das redes de transporte e a concentração de postos de trabalho são concomitantes com fraca e tendencialmente decrescente densidade residencialque tem vindo a alastrar pela cidade de Lisboa (Soares, 2003).

A perda de população nas freguesias da cidade de Lisboa, iniciada nos anos 60, é o obverso da intensa e acelerada suburbanização ocorrida nos seus arredores. Quando colocada em relação com o processo de urbanização dos concelhos vizinhos, a perda de população é reveladora da ção de um território com características metropolitanas. É o igualmente o facto de programas genéricos como o RECRIA terem sendo introduzidos em Alfama e noutros espaços residenciais históricos da cidade de Lisboa, ou o facto de iniciativas pontuais como Lisboa '94 - Capital Europeia da Cultura incluíram renovação de edificado histórico da cidade. $\mathrm{O}$ arranque da renovação urbana da Lisboa herdada é revelador dos efeitos da inversão espacial da estrutura de povoamento, à época já dominada pelos concelhos limítrofes.
Mas a extensão e a intensidade da metropolização lisboeta encontra-se também expressa em outras duas tendências: a reconversão dos vestígios e da herança das antigas centralidades suburbanas dos arredores da cidade e a constituição de programas destinados a intervir em alguns dos seus territórios mais desqualificados. A orientação de projectos de renovação urbana para os antigos núcleos suburbanos - alguns deles, como Algés, Amadora, Oeiras ou Barreiro, em perda populacional no decénio 1991-2001 - é típica da primeira tendência e reveladora das tensões engendradas pela sua integração num território metropolitano onde a diferenciação socio-espacial progride e se acentua. Da segunda tendência, é bem emblemático o facto da freguesia do Cacém ter sido eleita território de intervenção do Programa POLIS. O caso evidencia a presença de uma questão premente e aguda: como intervir e qualificar o resultado do crescimento residencial suburbano de fraca qualidade ocorrido entre $1960 \mathrm{e}$ 1980? Questão de política urbana, certamente, mas que se cruza com a morfologia da metrópole, sobretudo com o objecto em análise - a sua estrutura de povoamento - e a sua relação com a transformação da forma urbana.

\section{Conclusão}

Em L'Histoire de l'Europe Urbaine, Guy Burgel argumenta que a suburbanização acelerada que marcou o devir das cidades europeias na segunda metade do século Xx implicou uma inversão espacial 
e demográfica que tem hoje particular importância para compreender as relações entre as cidades e as suas coroas suburbanas (Burgel, 2003: 678). Foi precisamente desta inversão espacial - e da mudança na estrutura de povoamento que a acompanha e organiza - que se deu conta ao longo do texto. Num primeiro momento, entendendo-a à maneira clássica como urbanização dos arredores. Num segundo momento, apreendendo-a enquanto articulação entre uma geografia da suburbanização de Lisboa e os tempos da sua consolidação e generalização. $\mathrm{E}$, num terceiro momento, reconstituindo-a detalhadamente, à escala da freguesia e ao longo dos últimos sessenta anos, através da análise à estrutura de povoamento da aglomeração de Lisboa.

O enfoque morfogenético dá a conhecer como de 1960 em diante os subúrbios citadinos de Lisboa contribuem para a emergência e mais tarde para a consolidação da metrópole de Lisboa. Ao tomar-se como escala de análise a freguesia obtém-se uma imagem precisa quer dos lugares que ao longo do tempo foram fixando população, quer da sua multiplicação e disseminação no território da aglomeração. A análise à estrutura de povoamento da aglomeração de Lisboa revela como, entre 1960 e 1981, os subúrbios citadinos se apresentam como territórios que em estreita relação com os transportes colectivos facultam aos residentes económica ligação à cidade. São, todavia, subúrbios citadinos em mutação: seja pela concentração populacional que evidenciam, seja pela pluralidade de formas de crescimento urbano que os transformam. Análise que revela também como entre 1981 e 2001 se constituem eixos de crescimento metropolitano que atravessam a aglomeração. O facto de no ano de 2001 metade da população da metrópole de Lisboa residir em trinta e oito freguesias que são contíguas ou vizinhas aos grandes eixos ferro e rodoviários é revelador da tradução territorial da morfogénese e da consolidação da metrópole. Por um lado, persiste a estruturação exercida pelos transportes colectivos - modo de deslocação que em muito contribui para que a forma embrionária da metrópole se constituís- se. Por outro lado, a estrutura de povoamento revela como o automóvel assume papel central na vida da metrópole e dos seus mais recentes territórios urbanizados - um dado convergente com a análise empreendida pelo Instituto Nacional de Estatística (2003) relativamente à mobilidade pendular na Área Metropolitana de Lisboa.

É justamente seguindo os traços morfológicos do povoamento e das vias de circulação rodoviária da metrópole de Lisboa que se encontram significativas mudanças nos subúrbios metropolitanos da capital. Evidenciam-se há já algum tempo os efeitos exercidos pelas infra-estruturas de comunicação e transporte na divisão do trabalho organizacional e na circulação de bens, informações e pessoas entre antigos e os novos espaços de trabalho na metrópole. Significativa parte dos últimos situa-se em territórios que até há bem pouco tempo eram arrabaldes de núcleos suburbanos. Com facilidade, o observador que circule ou se desloque ao longo das principais vias de circulação rodoviária constata a presença de estruturas de back-office mas igualmente sedes de empresas; campus universitários, laboratórios e espaços industriais de ponta mas igualmente campos de golfe; grandes superfícies comerciais e grandes superfícies cultivadas e exploradas por agro-indústria intensiva; lugares turísticos e lugares de lazer, mas também lugares de acumulação e distribuição de mercadorias - hubs, entrepostos e armazéns. Em suma, espaços que polarizam procura de mão-de-obra para actividades variadas e que exigem igualmente força de trabalho para a sua manutenção e para serviços a empresas e populações operando nos subúrbios metropolitanos. Transpondo para o contexto europeu a expressão cunhada por Joel Garreau (1991) para analisar o devir dos subúrbios norte-americanos, está-se perante a constituição de edge-suburbs (Buck et al. 2002). Trata-se de uma nova forma espacial metropolitana, cujas interacções com a estrutura de povoamento e com as condições da experiência urbana de vastos contigentes populacionais importa analisar. 


\section{Bibliografia}

BAPTISTA, Luís Vicente (1994), "Dominação demográfica no contexto do século xx português: Lisboa, a capital", Sociologia - Problemas e Práticas, n. ${ }^{\circ} 15$, pp. 53-77.

BAPTISTA, Luís Vicente (1996), A Cidade em Reinvenção: crescimento urbano e emergência das políticas sociais de habitação - Lisboa, século $X X$, Dissertação de Doutoramento em Sociologia, Lisboa Faculdade de Ciências Sociais e Humanas da Universidade Nova de Lisboa.

BAPTISTA, Luís Vicente (1999), Cidade e Habitação Social. O Estado Novo e o Programa das Casas Económicas em Lisboa, Oeiras, Celta Editora.

BASSAND, Michel (1997), Métropolisation et inégalités sociales, Lausanne, Presses Polytechniques et Universitaires Romandes.

BRITO, Raquel Soeiro de (1976), "Lisboa, esboço geográfico", Junta Distrital de Lisboa, Boletim Cultural n. ${ }^{\circ} 82$.

BUCK, Ian et al. (2002), Working Capital. Life and Labour in Contemporary London, London, Routledge

BURGEL, Guy (2003), "La ville contemporaine: de la Seconde Guerre mondiale à nos jours" in Pinol, Jean-Luc (dir.) Histoire de l'Europe Urbaine. De l'Ancien Régime à nos jours, Tome II, Paris, Seuil, pp. 553-807

CASTELLS, Manuel (1984), Problemas de Investigação em Sociologia Urbana, Lisboa, Presença.

CHAMPION, Tony (2001), "Urbanization, suburbanization, counterurbanization and reurbanization" em Paddison, Ronan (ed.) Handbook of Urban Studies, London, Sage, pp. 143-161.

CORTE-REAL, Álvaro (1973), Fetais, Pontinha, Santo António dos Cavaleiros. Três Tipos de Subúrbio, Dissertação de Licenciatura em Geografia, Lisboa, Faculdade de Letras de Lisboa.

CRUZ, Maria Alfreda (1973), A Margem Sul do Estuário do Tejo, s/l, s/ed.

FERRÃO. João et al. (2003), “Uma metrópole em transição: novo perfil produtivo, novos espaços económicos" em Tenedório, José António (dir.) Atlas da Área Metropolitana de Lisboa, Lisboa, AML, pp. 167-187.
FERREIRA, Vítor Matias (1987), A Cidade de Lisboa: de Capital do Império a centro da Metrópole, Lisboa, Dom Quixote.

FERREIRA, Vítor Matias (1994), "Inovação Social e Mudança Urbana na Lisboa Contemporânea. Uma aproximação sucinta à inovação urbana em Lisboa (1850-1980", Ler História, n. ${ }^{\circ} 26$, pp. 151-169.

GARREAU, Joel (1991) Edge City: Life on the New Frontier, New York, Doubleday \& Company.

HALBWACHS, Maurice (1970 [1938]), Morphologie Sociale, Paris, Armand Colin. http://classiques.uqac.ca/classiques/ Halbwachs_maurice/morphologie/morphologie.html

INSTITUTO NACIONAL DE ESTATÍSTICA (2003), Movimentos Pendulares e Organização do Território Metropolitano: Área Metropolitana de Lisboa e Área Metropolitana do Porto, 1991-2001, Lisboa, INE.

LOBO, Margarida Sousa e Nuno Portas (1970), «"Níveis sociourbanísticos no subúrbio de Lisboa-cidade", Informação Social, n. ${ }^{\circ} 19$, pp. $54-75$

MOURA, Raul Vilaça e Gilberto Gomes (1999), “Caminhos de Ferro" em Barreto, António e Maria Filomena Mónica (coord.) Dicionário de História de Portugal. Vol. VII, Suplemento $A / E$, Porto, Figueirinhas, pp. 223-227

NUNES, João Pedro Silva (2007), Florestas de Cimento Armado. Os Grandes Conjuntos Residenciais e a Constituição da Metrópole (Lisboa, 1955-1981), Dissertação de doutoramento em Sociologia, Lisboa, Faculdade de Ciências Sociais e Humanas da Universidade Nova de Lisboa.

SALGUEIRO, Teresa Barata (2001), Lisboa, Periferia e Centralidades, Oeiras, Celta Editora.

SOARES, Nuno (2003), "Habitação" em Tenedório, José António (dir.) Atlas da Área Metropolitana de Lisboa, Lisboa, AML, pp. 149-165.

SOLÀ-MORALES, Manuel (1997), Las formas del crecimiento urbano, Barcelona, Edicions de la Universitat Politècnica de Catalunya.

STÉBÉ, Jean-Marc (1999), La Crise des Banlieues: Sociologie des Quartiers Sensibles, Paris, PUF (col. Que sais-je?). 